\title{
On the significance of giant somatosensory evoked potentials in cortical myoclonus
}

\author{
JC ROTHWELL, JA OBESO, CD MARSDEN \\ From the University Department of Neurology, Institute of Psychiatry and King's College Hospital Medical \\ School, Denmark Hill, London, UK SE5 $8 A F$
}

SUMMARY Four patients with cortical myoclonus were studied. All had reflex muscle jerking and grossly enlarged somatosensory evoked responses (SEPs) following electrical stimulation of the digital nerves. In addition, three of the patients had spontaneous or action-induced myoclonus. Back-averaging the EEG from these spontaneous muscle jerks showed a large positive wave over the contralateral somatomotor cortex which preceded the jerk by about $20 \mathrm{~ms}$. Administration of lisuride $(0.1 \mathrm{mg}$ iv) reduced the severity of the reflex and spontaneous myoclonus, but had no effect on, or increased the size of the SEP. Two of the patients also received $1 \mathrm{mg}$ clonazepam iv. As with lisuride, the severity of myoclonic jerking was reduced although the size of the SEP was increased. It is concluded that the usual association between giant SEPs and reflex muscle jerking can be abolished by acute administration of lisuride and clonazepam in patients with cortical myoclonus.

A striking abnormality of the somatosensory evoked potential (SEP) is its pathological enlargement in certain types of myoclonus ${ }^{1-3}$ and epilepsy. ${ }^{4-6}$ The origin and significance of these giant potentials is a matter of debate, but they probably represent the synchronous depolarisation or discharge of a large group of neurones in the sensori-motor cortex. Not all patients with myoclonus have enlarged SEPs. ${ }^{5}$ In those who do, the size of these responses often correlates with the degree of therapeutic control of the muscle jerks ${ }^{7-9}$. When the myoclonus is wellcontrolled, the size of the SEP is reduced. However, while such a general correlation exists, Halliday ${ }^{4}$ pointed out that, on occasion, large SEPs may not be followed by myoclonic jerks. He speculated that this might be due to a refractory state of spinal cord motoneurons.

The stimulus used to evoke the SEP also produces a reflex myoclonic jerk in such patients. Kugelberg and Widen ${ }^{2}$ observed in one patient that removal of a small zone of the motor cortex abolished the enlarged SEP and the stimulus-evoked long latency muscle jerking in the leg. Several authors ${ }^{34610}$ subsequently have confirmed that the interval between

Address for reprint requests: Prof CD Marsden, Department of Neurology, Institute of Psychiatry, De Crespigny Park, Denmark Hill, London SE5 8AF, UK.

Received 26 March 1983. Accepted 17 July 1983 the early cortical components of the large SEP and the muscle jerks (about $20 \mathrm{~ms}$ for the forearm muscles) is the same as the latency of muscle activation produced by direct motor cortex stimulation. ${ }^{11} 12$ This form of myoclonus has been described as cortical reflex myoclonus. ${ }^{101314}$

Many patients with enlarged SEPs also have spontaneous myoclonic jerks. In these individuals a large potential in the EEG frequently precedes each jerk. Back-averaging the EEG activity preceding the spontaneous muscle jerks reveals a potential that has the same form and spatial location as the primary complex of the enlarged SEP; it precedes the muscle jerk by the same time interval. ${ }^{610}$ Such patients are said to have spontaneous cortical myoclonus. ${ }^{14}$ Many patients with cortical myoclonus exhibit both reflex and spontaneous jerks, but the two do not always occur together.

The simplest conclusion from these observations is that the giant SEP, and its equivalent spontaneous cortical potential, are in some way responsible for the myoclonus. The enlarged components of the SEP could be caused by a synchronised discharge of cortical pyramidal tract cells, which might also generate a volley conducted down the direct projection to spinal alpa-motoneurones to evoke the myoclonic jerk. However, during the course of investigations into the treatment of this type of myoclonus, we found that the giant SEPs and the myclonic jerks 
responded differently to the administration of lisuride, a dopamine and serotonin agonist. Lisuride could markedly reduce the frequency and severity of myoclonic jerking whilst at the same time the amplitude of the SEP was unaffected or even increased. This chance observation of a dissociation between the size of the SEP and the muscle jerks led to a more detailed investigation of the results of intravenous administration of lisuride and clonazepam in four patients with cortical myoclonus.

\section{Methods}

The clinical details of the four patients referred to in this paper have been described in a previous pharmacological paper. ${ }^{15}$ A brief summary is provided in table 1 .

Neurophysiological studies included routine EEG, polymyography, back-averaging of the EEG activity preceding spontaneous jerks, and somatosensory evoked potentials (SEPs). Preliminary EMG recordings were made from up to eight muscles responsible for the myoclonic jerking, using bipolar silver/silver chloride electrodes placed $2 \mathrm{~cm}$ apart over the belly of the muscles. From these records, one of the muscles most regularly involved in each myoclonic jerk was selected to trigger collection of EEG data for back-averaging. Only muscles with a well-defined burst of activity in each jerk were chosen, so as to reduce the amount of "jitter" in the trigger point. SEPs were recorded following stimulation with ring electrodes of the digital nerves of the first two fingers of the (most) affected hand at approximately $1.5 \times$ sensory threshold. Stimuli were given randomly every $2-3 \cdot 5$ seconds. SEPs were the average of 128-256 stimuli. There is some difficulty in labelling the various components of the SEP in patients with grossly abnormal potentials. In this paper we have chosen to designate the major peaks by their polarity and sequence $(\overline{\mathrm{NI}}, \overline{\mathrm{Pl}}, \overline{\mathrm{N} 2}$ etc-see fig 1$)$ in order to avoid equating any of the myoclonic potentials with those seen in normal individuals $(\overline{\mathrm{N} 20}, \overline{\mathrm{P} 25} / \overline{\mathrm{P} 30}$, $\overline{\mathrm{N} 35}$ ).

The EEG was recorded from silver/silver chloride electrodes on the scalp. The traces shown in this paper were all referred to linked mastoid reference or F2, although we routinely verified the localisation of the EEG potentials to the sensorimotor area of the contralateral scalp using a bipolar montage. The signals were low pass filtered at $2 \cdot 5$ $\mathrm{kHz}$ with a time constant of $1.0 \mathrm{~s}$, and data were collected by a PDP 12 computer using programmes written by $\mathrm{Mr}$
HB Morton. Up to eight channels of EEG and EMG data were collected over a $250 \mathrm{~ms}$ time period with a sampling rate of $1 \mathrm{kHz}$ per channel. This is sufficiently rapid to resolve the medium latency SEP peaks analysed here. Detailed analysis of early cortical and far-field potentials, and cervical evoked potentials was carried out using a 50 ms sweep with a sampling rate of $5 \mathrm{kHz}$. When backaveraging the EEG from spontaneous muscle jerks, each single trial was collected separately and then averaged later. In this way any record showing movement artefact could be rejected by eye, and the data could be separated out into groups according to the size of the recorded muscle jerk. Thus we could analyse the relationship between the size of the muscle jerk and the preceding cortical event. 64-128 trials were averaged for each patient.

\section{Results}

The clinical and electrophysiological data from all four patients are summarised in tables 1 and 2. Each patient had reflex jerking in response to a standardised electrical stimulus applied to the digital nerves of the first two fingers of the affected side. This consisted of a small $\overline{\mathrm{N} 1}$ response followed by much larger $\overline{\mathrm{P} 1}, \overline{\mathrm{N} 2}$ responses. The latency and distribution of $\overline{\mathrm{N} 1}$ response suggests that it probably was analogous to the $\overline{\mathrm{N} 20}$ of normal individuals. If so, it was of normal latency in all four patients. In two of the patients it was also of normal amplitude whereas it was slightly increased in size in the other two. Early cervical potentials were unaffected (fig 1). Note that the large, later, components of the cervical SEP in fig $1 \mathrm{~B}$ are due to activity recorded from the scalp reference electrode $\left(F_{z}\right)$. The latencies to the $\overline{\mathrm{P} 1}$ and $\overline{\mathrm{N}} 2$ components were slightly longer than to either of the possible normal equivalents, $\overline{P 25} / \overline{\mathrm{P} 30}$ and $\overline{\mathrm{N} 35}$, but their amplitudes were far above those of any medium latency SEPs seen in normal subjects.

The EMG bursts were of short duration, and often occurred synchronously in antagonist muscles. In addition, in three of the four cases, a time-locked cortical potential was recorded maximal over the contralateral sensorimotor cortex preceding spontaneous or action-induced jerks (fig 2). The fourth patient (CG) did not have spontaneous jerks. On

Table 1 Clinical characteristics of 4 patients with cortical myoclonus

\begin{tabular}{|c|c|c|c|c|c|c|}
\hline Patient & Sex & $\begin{array}{l}\text { Age } \\
\text { (years) }\end{array}$ & $\begin{array}{l}\text { Distribution of } \\
\text { myoclonus }\end{array}$ & $\begin{array}{l}\text { Type of } \\
\text { myoclonus }\end{array}$ & Aetiology & $\begin{array}{l}\text { Associated } \\
\text { features }\end{array}$ \\
\hline$\overline{\mathrm{EA}}$ & $F$ & 56 & $\begin{array}{l}\text { Multifocal and } \\
\text { Generalised }\end{array}$ & \multirow{4}{*}{$\begin{array}{l}\text { Action } \\
\text { Spontaneous } \\
\text { Reflex } \\
\text { Action } \\
\text { Spontaneous } \\
\text { Reflex } \\
\text { Spontaneous } \\
\text { Reflex }\end{array}$} & Head-trauma & None \\
\hline CG & $\mathrm{F}$ & 52 & Multifocal & & Unknown & \multirow{3}{*}{$\begin{array}{l}\text { Ataxia } \\
\text { Dystonic hand } \\
\text { and Epilepsy } \\
\text { Epilepsy }\end{array}$} \\
\hline JB & $\mathrm{F}$ & 34 & Focal (right hand) & & Unknown & \\
\hline PM & $\mathbf{M}$ & 19 & Focal (left hand) & & Unknown & \\
\hline
\end{tabular}




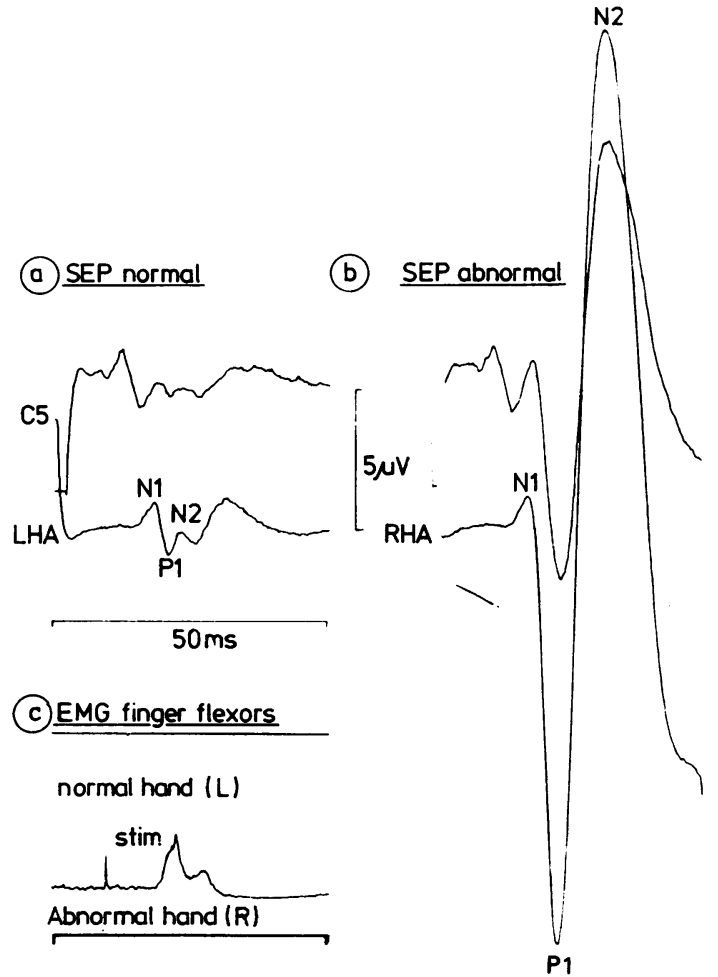

the basis of our previous classification, ${ }^{1417}$ these patients were designated as having cortical myoclonus.

The sizes of both the reflex muscle jerks and of the SEPs were related to the stimulus intensity. In each individual, in averaged records, there was a clear relationship between the size of the $\overline{\mathrm{P} 1}$ and $\overline{\mathrm{N} 2}$ components of the evoked cortical response and the EMG jerk (fig 3A). In contrast, in individual runs there often was a discrepancy between the two events (fig 3B). However, when the size of the $\overline{\mathrm{P} 1}-\overline{\mathrm{N}} 2$ response was measured in a large series of single records, there was a correlation with the size of the muscle jerks (fig 3C). This correlation was not evident if the $\overline{\mathrm{N}} 1-\overline{\mathrm{P}} 1$ response was measured instead.

In one patient we also were able to observe the relation of cortical activity to the size of spontaneous muscle jerks. In single records there frequently was a discrepancy between the size of the cortical event and the EMG jerk. However, like the reflex jerks referred to above, in averaged records there was correspondence between the two. Large EMG bursts were preceded by large cortical waves recorded from the contralateral cortex (fig 4).

Each patient received an injection of lisuride $(0.1$ $\mathrm{mg}$ iv). In all cases there was a marked reduction in
Fig. 1 Evoked potentials $(A, B)$ and reflex $E M G$ responses $(C)$ following electrical stimulation of the digital nerves of the left, normal, $(A$, and upper trace in $C)$, or right, abnormal, $(B$, and lower trace in $C)$ fore-finger of one patient $(J B)$. Evoked potentials are the average of 999 stimuli recorded from the cervical cord (C5) and contralateral somatosensory hand area (RHA, LHA), referred to an electrode at $F z$. The scalp records are labelled for the furst and second negative deflections $(N 1, N 2)$ and the first positive deflection (P1). EMG records (C) are on a different time scale and are the average of 128 rectified responses from surface electrodes over the flexor carpi radialis. This patient had reflex myoclonus in the right hand (see lower trace in C) and an extremely large P1-N2 component of the SEP over the contralateral hemisphere following right finger stimulation. In contrast the N1 component, which was probably analogous to the $\overline{N 20}$ of normal subjects, and all early cervical components of the $S E P$ were normal and of equal amplitude on both sides. Stimulation occurs at $0 \mathrm{~ms}$ in $A$ and $B$, and at $50 \mathrm{~ms}$ (stim) in $C$.

the incidence and degree of spontaneous and action-induced myoclonic jerking, as evaluated clinically (table 3). The amplitude of the reflex EMG bursts evoked by digital stimulation decreased with lisuride in three patients but was only slightly reduced in one (case EA). The size of the $\overline{\mathrm{P} 1}-\overline{\mathrm{N}} 2$ component of the SEP was greater after lisuride in three cases but there was no change in the other patient (PM). Figure 5 shows the individual results from two representative patients (JB and PM) before and after administration of lisuride. In JB there was a considerable reduction in the evoked myoclonic EMG burst with an increase in the amplitude of the $\overline{\mathrm{P} 1}-\overline{\mathrm{N} 2}$ component of the SEP (fig 5A). In the other patient (PM) the jerk virtually disappeared without a reduction in the amplitude of the SEP (fig 5B).

On a different occasion two patients (JB and CG) received $1 \mathrm{mg}$ of clonazepam intravenously. Their spontaneous and action-induced jerks also improved a few minutes after the injection. The amplitude of reflex jerks evoked by digital nerve stimulation was reduced in both cases, but there was a concomitant increase in the size of the SEPs. (fig 6A table 3). However, the spontaneous EEG brain wave preceding the jerks in patient (JB) was greatly reduced after clonazepam, (fig 6B), thus maintain- 
Table 2 Electrophysiological features

\begin{tabular}{|c|c|c|c|c|c|c|c|c|}
\hline & \multirow[t]{2}{*}{$\begin{array}{l}\text { Time-locked EEG } \\
\text { activity preceding } \\
\text { spontaneous myoclonus* }\end{array}$} & \multicolumn{3}{|c|}{$\begin{array}{l}\text { Peak latency (ms) of the } \\
\text { primary components of the } \\
\text { SEP† }\end{array}$} & \multicolumn{2}{|c|}{$\begin{array}{l}\text { Amplitude }(\mu V) \\
\text { of SEP primary } \\
\text { complex } \dagger\end{array}$} & \multicolumn{2}{|c|}{$\begin{array}{l}\text { EMG reflex bursts } \\
\text { evoked by electrical } \\
\text { stimulation } \ddagger\end{array}$} \\
\hline & & $N I$ & $P 1$ & $N 2$ & $N 1$ & $P I / N 2$ & $\begin{array}{l}\text { Latency } \\
(\mathrm{ms})\end{array}$ & $\begin{array}{l}\text { Duration } \\
\text { (ms) }\end{array}$ \\
\hline $\begin{array}{l}\text { EA } \\
\text { CG } \\
\text { JB } \\
\text { PM }\end{array}$ & $\begin{array}{l}\text { Yes }(17 \mathrm{~ms}) \\
\text { Not done } \\
\text { Yes }(22 \mathrm{~ms}) \\
\text { Yes }(21 \mathrm{~ms})\end{array}$ & $\begin{array}{l}22 \\
21 \\
22 \\
22\end{array}$ & $\begin{array}{l}30 \\
29 \\
30 \\
30\end{array}$ & $\begin{array}{l}45 \\
39 \\
43 \\
44\end{array}$ & $\begin{array}{l}2 \cdot 5 \\
2 \cdot 2 \\
1 \cdot 5 \\
1 \cdot 5\end{array}$ & $\begin{array}{l}12 \\
25 \\
30 \\
45\end{array}$ & $\begin{array}{l}45 \\
46 \\
52 \\
50\end{array}$ & $\begin{array}{l}25-50 \\
50-60 \\
25-50 \\
25-75\end{array}$ \\
\hline $\begin{array}{l}\text { Normal values } \\
(\text { mean } \pm 1 \mathrm{SD})\end{array}$ & & $\begin{array}{l}\overline{N 20} \\
22 \pm 1 \cdot 5\end{array}$ & $\begin{array}{l}\overline{\mathrm{P} 25} / \overline{\mathrm{P} 30} \\
26 \pm 3 \cdot 2\end{array}$ & $\begin{array}{l}\overline{N 35} \\
34 \pm 3 \cdot 8\end{array}$ & $0 \cdot 8 \pm 0 \cdot 4$ & $2 \cdot 8 \pm 0 \cdot 4$ & & \\
\hline
\end{tabular}

*The time between the EEG wave and the spontaneous myoclonic jerk was estimated in averages of 64-128 single records, as the interval between the peak of the positive EEG wave and the onset of the EMG burst.

TTe latencies and amplitudes of the SEP were determined in averages of $128-256$ responses to stimulation of the index and middle fingers at 1.5 times sensory threshold, recording the EEG from opposite sensori-motor cortex. The amplitude ( $\mu \mathrm{V})$ of the N1 component was measured from the average basal EEG level to the peak of the first negative wave. P1/N2 was measured peak to peak. The size range of these responses measured in consecutive averages of 64 responses, was $\pm 10 \%$ (N1) and $\pm 15 \%$ (P1/N2).

$\ddagger$ The average latencies, and range of durations of the EMG myoclonic bursts in finger flexors (EA,CG,JB) or 1st dorsal interosseous (PM) obtained by digital nerve stimulation were measured from $32-64$ responses.

The normal values are those for the nearest equivalent cortical potentials recorded in normal individuals, quoted by Desmedt, ${ }^{16}$ and verified in our own laboratories.

ing the relationship between the size of the jerks and spontaneous cortical discharges.

In patient JB we also tried to test whether these electrophysiological effects of clonazepam were accompanied by any change in the excitability of the alpha motoneuron pool. To do this, it was not possible to examine the muscles in the jerking, ipsilateral arm. However, $\mathrm{H}$-wave and $\mathrm{M}$-wave recruitment curves recorded from the contralateral left finger flexor muscles were unaffected by the injection of clonazepam (fig 7). Thus clonazepam did not appear to have any general effects on excitability at the spinal cord level.

\section{Discussion}

Not all patients with myoclonus have enlarged SEPs, but in those who do, the size of the evoked response in any individual generally is correlated with the severity of muscle jerking. The results in this study show that acute iv administration of lisuride or clonazepam can dissociate this relationship. Large SEPs can persist or even get bigger when the muscle jerking has been considerably reduced.

The electrophysiological feaures of the four patients described here were, (1) short duration (less than $100 \mathrm{~ms}$ ) EMG bursts which often were synchronous in antagonist muscles, (2) greatly enlarged SEPs; the peak of the P1 component preceded the onset of reflexly-evoked jerks by 15-22 $\mathrm{ms}$, and (3) focal EEG potentials over the contralateral scalp; the peak of these potentials preceded the onset of spontaneous jerks by 17-22 ms. These findings are consistent with our classification of cortical myoclonus. ${ }^{101417}$

It has been tempting to assume that the giant
SEPs cause the myoclonic jerks. The latencies between the peak of P1, or the equivalent EEG positive wave preceding spontaneous jerks, and the onset of the EMG bursts responsible for the myoclonus are similar to conduction time in fast corticospinal (pyramidal) pathways. The most recent measurements on normal, awake subjects, using high voltage stimulation of the motor cortex through the scalp give latencies of about $23 \mathrm{~ms}$ for activation of intrinsic hand muscles from the brain. ${ }^{12}$ The latency of activation of the same muscles from stimulation of the cervical cord is some 5-6 ms less, which would suggest a fast-conducting, and probably monosynaptic, activation of the spinal alphamotoneurones. The giant SEPs might be considered to represent an abnormal synchronous discharge of motor cortex pyramidal tract neurons which could activate the spinal motoneurones via the same monosynaptic pathway, and perhaps also by other, fast conducting polysynaptic routes. If this were so then lisuride and clonazepam could dissociate the size of the recorded cortical event from that of the reflex muscle jerk in three main ways:

(1) If the cortical event represents the discharge of pyramidal neurons in motor cortex which cause the muscle jerk, these drugs could act between the motor cortex and the muscle, for example in the spinal cord. However, in one patient we were able to show that the $\mathrm{H}$-reflex threshold and recruitment curve was unchanged after administration of clonazepam, indicating that spinal motoneuron excitability was not altered, despite a decrease in the myoclonic jerks. Nevertheless, it may be that pathways other than the monosynaptic projection to the spinal alpha-motoneurons are involved. The drugs could then act preferentially on interneurons 

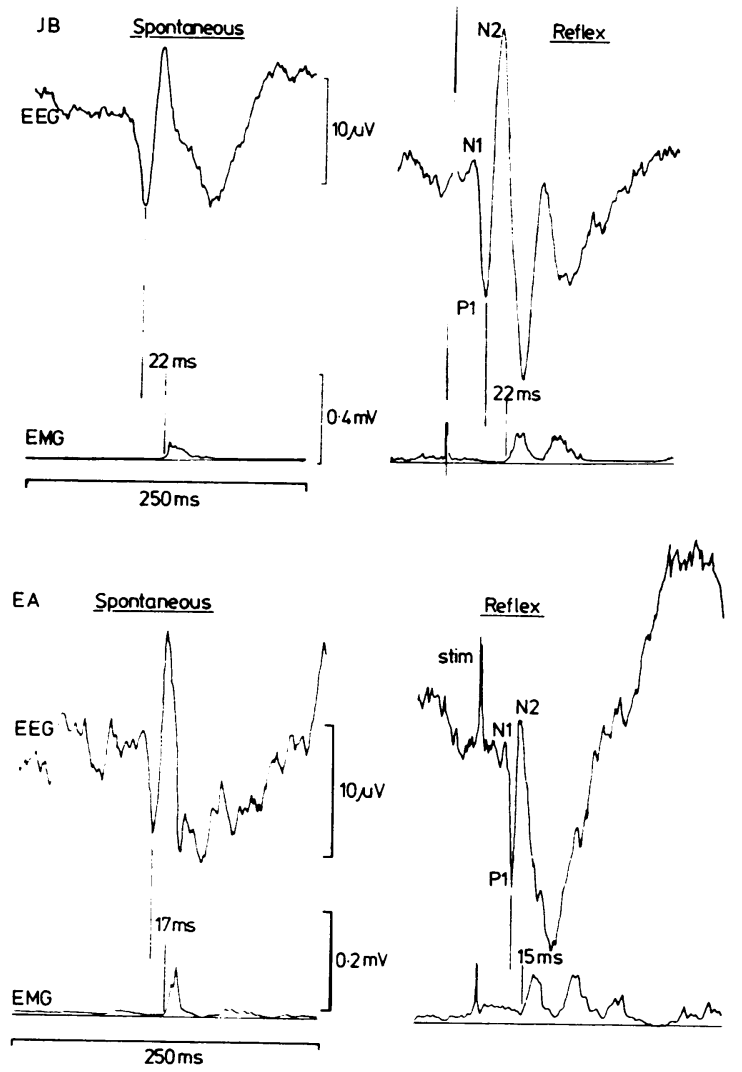

Fig 2 Average (of 64-128) EMG and EEG events associated with spontaneous (left traces) and reflexly-evoked (right traces) jerking in three patients (JB, $E A, P M)$. Spontaneous jerks were back-averaged from a trigger point on the rectified EMG record. Reflex jerks were elicited by giving electrical stimuli (stim) to the forefinger, $50 \mathrm{~ms}$ after the start of the recording sweep. The time interval between the large positive wave in the EEG and the start of the myoclonic EMG burst is indicated in all records. EMGs taken from flexor carpi radialis (patients JB, EA) or first dorsal interosseous (patient $P M$ ). EEG records from the contralateral somatosensory hand area $(7 \mathrm{~cm}$ lateral on a line joining the external auditory meatus to a point $2 \mathrm{~cm}$ behind the vertex), referred to a linked mastoid reference.
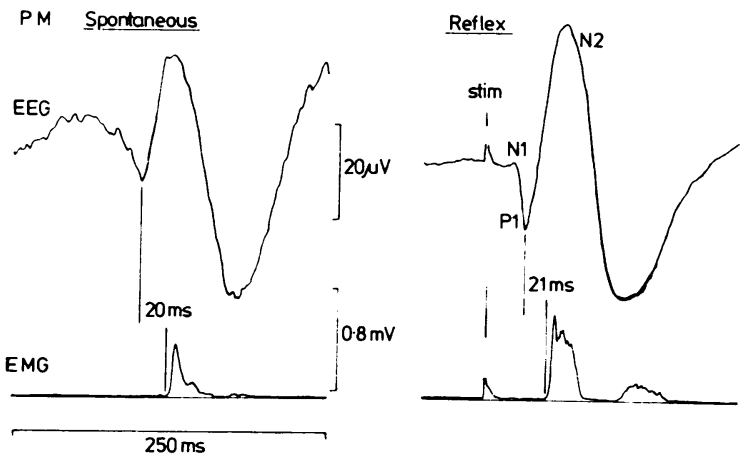


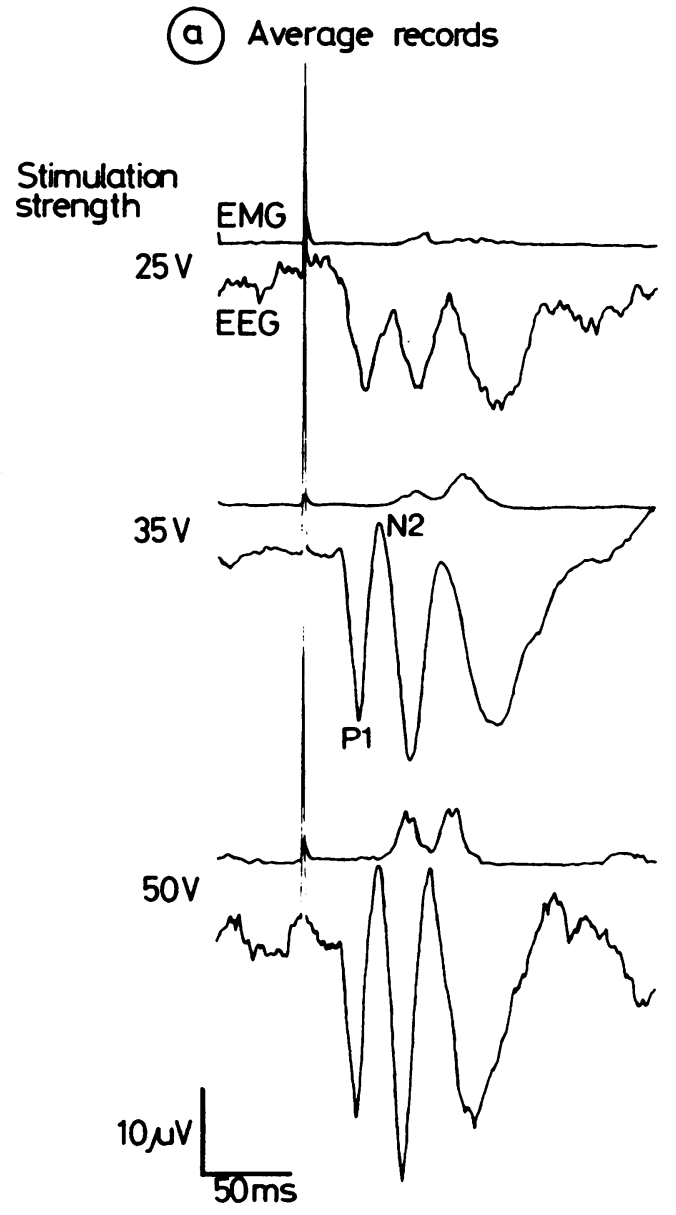

(b) Single records

EMG
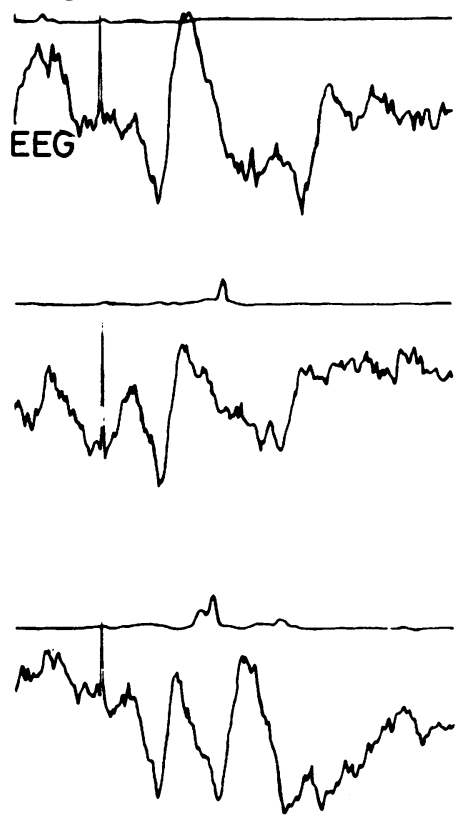

40رvV

$50 \mathrm{~ms}$

Fig 3 The relationship between the size of the P1-N2 component of the SEP and the size of the reflexly-evoked myoclonic EMG burst in patient JB. In A, the traces are the average of 128 sweeps and show how the size of both the EEG and EMG event increase together as the intensity of finger stimulation changes from 25-50V (200 $\mu$ s pulse width). In $B$, are three pairs of single records, each made at a stimulation intensity of $35 \mathrm{~V}$. In single sweeps there is frequently a discrepancy between the size of the $P 1-N 2$ wave and the reflex EMG burst. In $C$, the size of the EMG response in single records (integrated, rectified records) has been plotted against the size of the P1-N2 component of the $S E P$, measured in 80 trials. There is a good deal of variability in the size of the two events, although the relationship is significant overall (correlation coefficient $=$ $0.3 ; p<0.05)$. EEG records from the somatosensory hand area, referred to a linked mastoid reference. EMG from flexor carpi radialis.

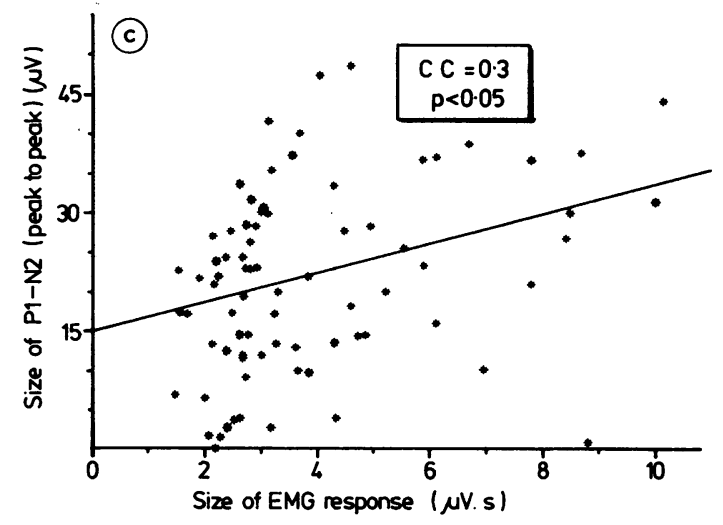



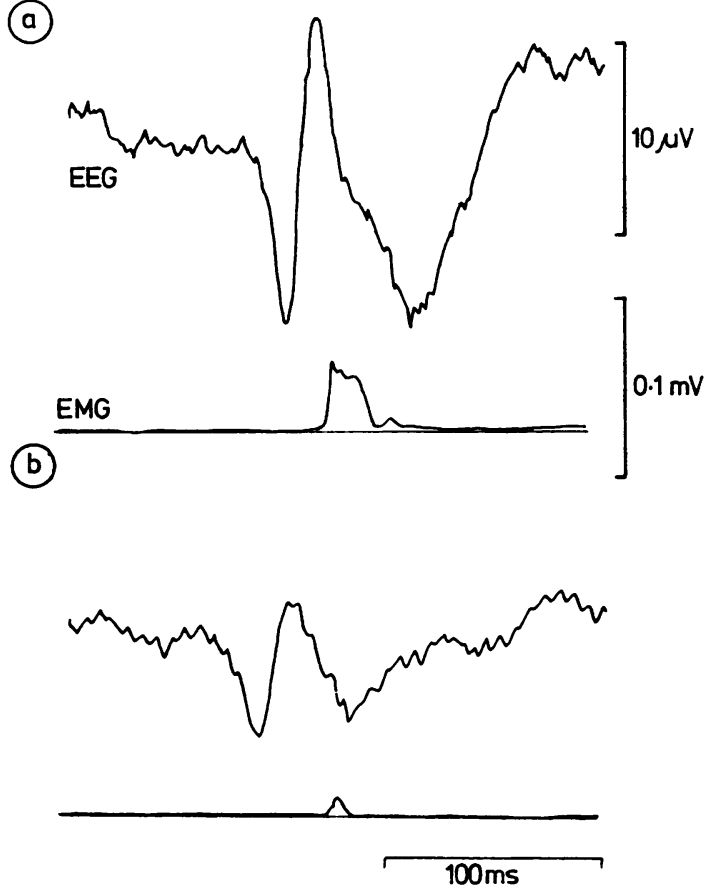

Fig 4 The relationship between the average size of spontaneous $E M G$ jerks and preceding cortical potentials in averaged records from patient $J B$. In $A$, are the records from the first investigation; in $B$, from a later investigation when the patient was well-controlled and jerking much less frequently. Traces are the average of 128 sweeps. EEG and EMG channels as in fig 3.

Table 3 Effect of lisuride and clonazepam on the amplitude of the somatosensory evoked potentials and of the EMG of the muscle jerks

\begin{tabular}{|c|c|c|c|c|c|c|}
\hline \multirow[b]{2}{*}{ Lisuride } & \multirow{2}{*}{$\begin{array}{l}\text { Patient } \\
\text { EA } \\
\text { CG } \\
\text { JB } \\
\text { PM }\end{array}$} & \multirow{2}{*}{$\begin{array}{l}\begin{array}{l}\text { Clinical response of } \\
\text { spontaneous and } \\
\text { reflex myoclonus* }\end{array} \\
\text { Dramatic } \\
\text { Moderate } \\
\text { Dramatic } \\
\text { Moderate }\end{array}$} & \multicolumn{2}{|c|}{$\begin{array}{l}\text { Amplitude of SEP } \\
(P 1-N 2 \text { in } \mu V) \dagger\end{array}$} & \multicolumn{2}{|c|}{$\begin{array}{l}\text { Amplitude of } \\
\text { myoclonic EMG } \\
\text { burst } \ddagger\end{array}$} \\
\hline & & & $\begin{array}{l}\text { Control } \\
12 \\
25 \\
30 \\
45\end{array}$ & $\begin{array}{l}\text { Drug } \\
18 \\
32 \\
42 \\
43\end{array}$ & $\begin{array}{c}\text { Control } \\
2 \cdot 3 \\
6 \cdot 4 \\
4 \cdot 2 \\
10 \cdot 0\end{array}$ & $\begin{array}{l}\text { Drug } \\
1.8 \\
1.0 \\
1.8 \\
0.5\end{array}$ \\
\hline \multicolumn{7}{|c|}{ Clonazepam } \\
\hline & $\begin{array}{l}\text { CG } \\
\text { JB }\end{array}$ & $\begin{array}{l}\text { Moderate } \\
\text { Dramatic }\end{array}$ & $\begin{array}{l}25 \\
30\end{array}$ & $\begin{array}{l}33 \\
44\end{array}$ & $\begin{array}{l}6 \cdot 2 \\
4 \cdot 2\end{array}$ & $\begin{array}{l}1 \cdot 3 \\
0 \cdot 2\end{array}$ \\
\hline
\end{tabular}

*Clinical Response: mild = less than $20 \%$ improvement; moderate = obvious benefit with demonstrable (50\%) reduction in disability; dramatic = striking reduction in myoclonus resulting in marked improvement in disability.

tThe amplitudes of the SEP were determined in averages of 128-256 responses to stimulation of the index and middle fingers at 1.5 sensory threshold, recording the EEG from the opposite sensorimotor cortex. The amplitude $(\mu \mathrm{V})$ was measured from the peak of the P1 wave to the peak of the $\mathrm{N} 2$ wave. The range in size of these responses in consecutive averages of 64 trials was about $\pm 15 \%$.

¥The amplitudes of the EMG myoclonic bursts in finger flexors (EA, CG, JB) or 1st dorsal interosseous (PM) obtained by digital nerve stimulation were measured from averages of 32-64 responses as the integral (in $\mu$ V.s) for the duration of the EMG complex. 

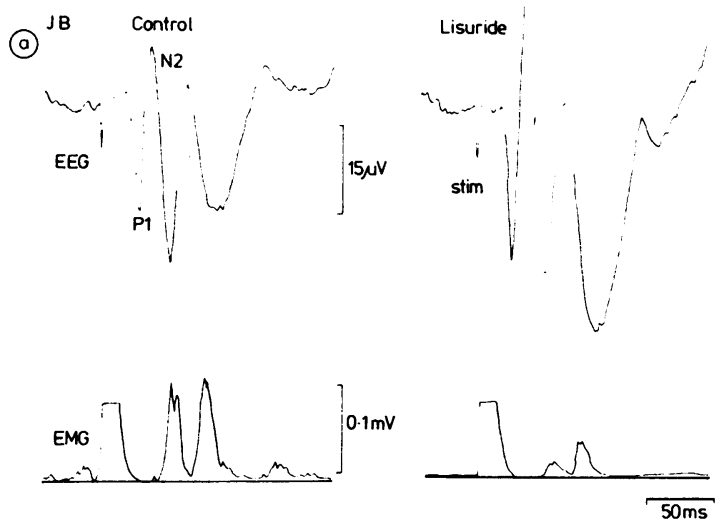

Fig. 5 The effect of lisuride on the size of reflexly-evoked muscle jerks and the size of the SEP in two patients $(J B, t o p$ $P M$, bottom). Records on the left show the average of 128 responses to forefinger stimulation before the injection. Records on the right show the responses 20-30 min
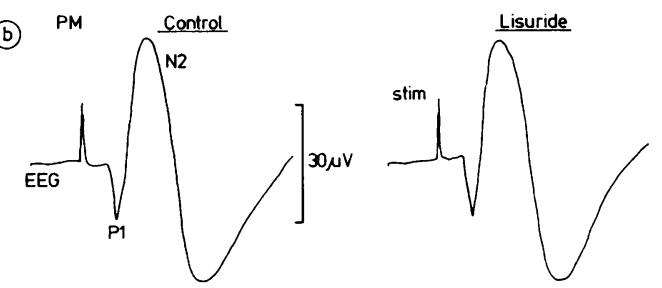
following administration of lisuride $(0 \cdot 1 \mathrm{mg}$ iv) Stimulation given $50 \mathrm{~ms}$ after start of sweep (stim). EEG records from contralateral somatosensory hand area, referred to a linked mastoid reference. EMGs from flexor carpi ulnaris $(J B)$ or 1 st dorsal interosseous (PM).

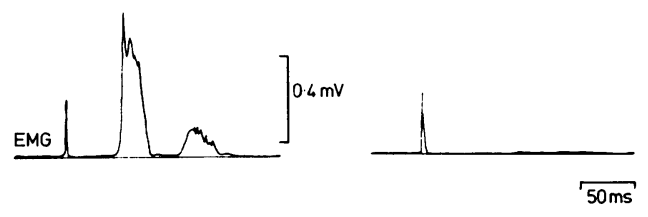

(a) Reflex
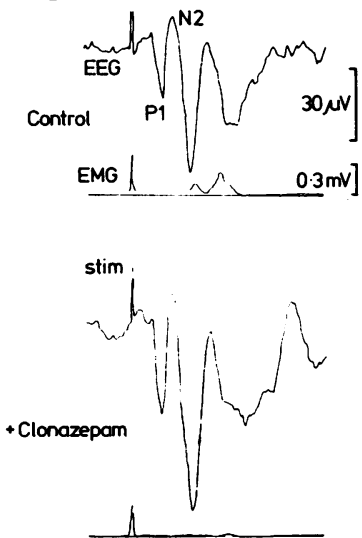

(b) Spontaneous
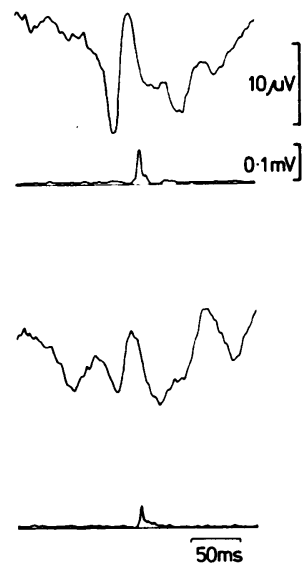

Fig. 6 The effect of clonazepam on the size of the EMG and $E E G$ events in reflex $(A)$ and spontaneous $(B)$ myoclonic jerks in patient $J B$. The top two traces show averaged records (128 sweeps in $A, 64$ sweeps in $B$ ) before, and the two bottom traces the averaged records 10-20 min after injection (1 mg iv) of clonazepam. After clonazepam, reflex EMG jerks are almost abolished, but the SEP $(P 1-N 2)$ is increased in size. In contrast clonazepam reduces the size of both EMG jerks and the preceding EEG event in spontaneous jerking. EEG and EMG electrodes as in fig 4. 


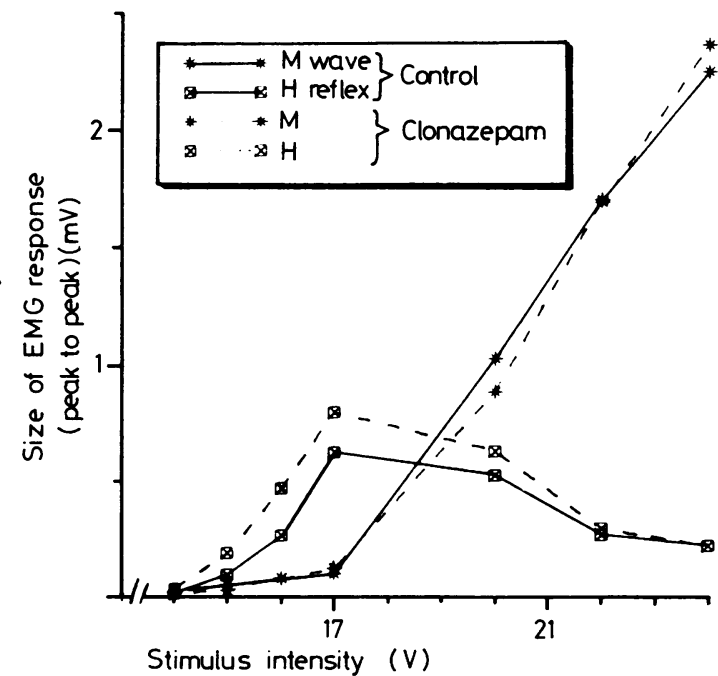

located within these pathways. However, such mechanisms cannot easily explain why the SEPs actually increased in size after lisuride and clonazepam in three of the four subjects.

(2) Following the same line of reasoning, it is possible that an indirect cortico-reticulo-spinal pathway might be involved in producing the myoclonic jerks rather than the direct monosynaptic corticospinal tract route. As pointed out above, such a pathway would have to be extremely rapidly conducting and its projections localised to very specific groups of alphamotoneurons within the cervical cord. If such a pathway does exist in man, then lisuride and clonazepam might well act at the reticular level rather than at the spinal cord or cortex.

(3) Turning to the giant $\overline{\mathrm{P} 1}-\overline{\mathrm{N}} 2$ primary component of the SEP, a positive wave recorded on the scalp generally is thought to be due to depolarisation of neurons deep in the cortex, thus creating a current sink relative to the cortical surface. The larger $P 1$ in cortical myoclonus might be due to strong, synchronous depolarisation of the cell bodies of pyramidal tract neurons in layer $\mathrm{V}$ of the motor cortex. Lisuride and clonazepam might act by facilitating the activity of inhibitory interneurons within the cortex. This activity could produce an enhancement of the P1 wave recorded at the scalp whilst at the same time depressing the output of the pyramidal tract neurons.

However, the source of the abnormal $\overline{\mathrm{P} 1}$ potential might not be in neurons of the motor cortex itself. The localisation of the giant $\overline{\mathrm{P} 1}-\overline{\mathrm{N}} 2$ complex in cortical myoclonus often is abnormal. For example, in the original patient described by Dawson, ${ }^{1}$ the
Fig. $7 \quad H$-reflex and $M$-wave recruitment curves in the flexor carpi radialis of patient $J B$ before (continuous lines) and after (dotted lines) clonazepam (1 mg iv). Stimuli were given to the median nerve at the elbow, and the muscles responses were recorded contralateral to the affected arm. At each stimulus intensity (pulse width $200 \mu \mathrm{s}$ ), ten responses were averaged and the size of the direct muscle response (M-wave) and monosynaptic reflex response ( $H$-wave) were measured. Clonazepam has no effect on the threshold or peak size of the responses.

source of the giant SEP was localised some $3 \mathrm{~cm}$ anterior to the central sulcus, well in front of the motor cortex. In another recent patient of our own with cortical myoclonus, in whom electrocorticography was undertaken prior to surgery, the source was found to lie in the sensory cortex behind the central sulcus. Such findings suggest that the giant SEP may reflect abnormal function of cerebral cortex remote from the motor area; in which case it is possible to see why lisuride and clonazepam might decrease jerks by reducing motor cortex discharges without decreasing the SEPs arising elsewhere. The drugs could act on the interconnection between the two areas of cortex. In other words, abnormal function of a distant area, for example the somatosensory cortex, or the supplementary motor area in frontal cortex, could drive pyramidal tract neurons in motor cortex to produce the myoclonic jerks.

Do the giant SEPs indicate that the area of cortex responsible for their source is the site of primary abnormality? Possibly so, but the giant SEPs could be due to abnormal input into that cortical area. The only electrophysiological evidence relevant to this point is the observation that the N1 was normal in size in two of the four patients we studied, and only slightly increased in the other two. By analogy with the $\overline{\mathrm{N} 20}$ of normal individuals, we think that the $\overline{\mathrm{N} 1}$ may represent the effect of the arrival of the thalamo-cortical volley into somatosensory cortex. ${ }^{18}$ Lisuride and clonazepam did not alter the size of the $\overline{N 1}$, suggesting that in the present patients their therapeutic actions were due to effects on intrinsic cortical mechanisms rather than on cortical inputs. However, the possibility that the giant $\overline{\mathrm{P} 1}-\overline{\mathrm{N} 2}$ com- 
plex is due to abnormal input of slow conducting afferents cannot be excluded. It must also be stressed that there may well be other types of cortical myoclonus which an abnormal input into the cortex generates a similar giant $\mathrm{P} 1-\mathrm{N} 2$ complex.

In conclusion, the data available suggest that the giant SEPs may arise either in the pyramidal tract cells of the motor cortex or in distant areas of cortex, the outputs of which then drive the pyramidal tract neurons to produce the myoclonic jerks. The action of clonazepam and lisuride, when administered acutely iv, could be at the level of this connexion or, if the large SEPs are generated in the motor cortex, they may act directly on inhibitory interneurons in the motor cortex or on other interneurons in the pathway to the spinal cord.

This work was supported by the Medical Research Council. We should like to thank Mr HC Bertoya and Mr R Miller for designing and building most of the equipment used in these experiments.

\section{References}

'Dawson GD. Investigations on a patient subject to myoclonic seizures after sensory stimulation.J Neurol Neurosurg Psychiatry 1947;10:141-62.

${ }^{2}$ Kugelberg E, Widen L. Epilepsia partialis continua. Electroenceph clin Neurophysiol 1965;6:503-6.

${ }^{3}$ Sutton GG, Mayer RF. Focal reflex myoclonus. J Neurol Neurosurg Psychiatry 1974;37:207-17.

${ }^{4}$ Halliday AM. The electrophysiological study of myoclonus in man. Brain 1967;90:241-84.

${ }^{5}$ Halliday AM. The neurophysiology of myoclonic jerking-a reappraisal. In: Charlton $\mathrm{MH}$, ed. Myoclonic Seizures 1975; pp 1-29 Amsterdam, Excerpta Medica.

- Shibasaki H, Yamashita Y, Kuroiwa Y. Electroencephalographic studies of myoclonus. Myoclonusrelated cortical spikes and high amplitude somatosensory evoked potentials. Brain 1978;101:447-60.

${ }^{7}$ Chadwick D, Hallett M, Harris R, Jenner P, Reynolds EM, Marsden CD. Manipulation of brain serotonin in the treatment of myoclonus. Brain 1977; 100: 45587.
${ }^{8}$ Fahn S. Postsynaptic action myoclonus: review of the literature and report of two new cases with response to valproate and estrogen. In: Fahn S, Davis JN, Rowland LP, eds. Advances in Neurology 1979; vol. 26: pp 49-84, New York, Raven Press.

${ }^{9}$ Halliday AM, Halliday E. Cerebral somatosensory and visual evoked potentials in different clinical forms of myoclonus. In: Desmedt JE, ed. Progress Clinical Neurophysiology. 1980; vol. 7 pp 292-310. Basel, Karger.

10 Hallett M, Chadwick D, Marsden CD. Cortical reflex myoclonus. Neurology (Minneap) 1979; 29: 1107-25.

" Pagni CA, Marassero E, Cabrini G, Ettore G, Infuso L. Physiopathology of stimulus sensitive myoclonus: a stereo-EEG study. Electroencephalogr Clin Neurophysiol 1971; 31: 176.

${ }^{12}$ Merton PA, Morton HB, Hill DK, Marsden CD. Scope of a technique for electrical stimulation of human brain, spinal cord, and muscle. Lancet 1982; i: 597600.

${ }^{13}$ Marsden CD, Merton PA, Morton HB. Is the human stretch reflex cortical rather than spinal? Lancet 1973; i: $759-61$.

${ }^{14}$ Marsden CD, Hallett M, Fahn S. The nosology and pathophysiology of myoclonus. In: Marsden CD, Fahn S eds. Movement Disorders 1981; pp 196-249. (Butterworth Scientific).

is Obeso JA, Rothwell JC, Quinn NP, Lang AE, Thompson $C$, Marsden $C D$. Cortical reflex myoclonus responds to intravenous lisuride. Clin Neuropharmacol (In press).

${ }^{16}$ Desmedt JE, Cheron G. Non-cephalic reference recording of early somatosensory potentials to finger stimulation in adult or ageing normal man: differentiation of widespread N18 and contralateral N20 from the prerolandic P22 and N30 components. Electroencephalogr Clin Neurophysiol 1981; 52: 553-70.

${ }^{17}$ Marsden CD, Obeso JA, Rothwell JC. The clinical neurophysiology of muscle jerks: myoclonus, chorea and tics. In: Desmedt JE ed. Brain and spinal mechanisms of movement control in man, new developments and clinical applications. New York: Raven Press, (1983).

${ }^{18}$ Desmedt JE, Cheron G. Somatosensory evoked potentials to finger stimulation in healthy octogenarians and in young adults: wave forms, scalp topography and transit times of parietal and frontal components. Electroencephalgr Clin Neurophysiol 1980; 50: 404-25. 